\title{
A Review on the Use of Hysteroscopy Tissue Removal System in Gynaecology
}

\section{Raksha Gururaj*}

Student at Ramaiah Institute of Technology, Bangalore, Karnataka, India

"Corresponding author: Raksha Gururaj, Student at Ramaiah Institute of Technology, Bangalore, Karnataka, India

Citation: Gururaj R (2021) A Review on the Use of Hysteroscopy Tissue Removal System in Gynaecology. Gynecol Obstet Open Acc 5: 142. DOI: 10.29011/2577-2236.100142

Received Date: October 25, 2021; Accepted Date: November 12, 2021; Published Date: November 17, 2021

\begin{abstract}
Intrauterine pathologies have become the common cause of gynaecological visits. These pathologies, if not treated can increase the rates of infertility and the risk of endometrial cancer. Surgical resection of intrauterine pathologies including polyps, fibroids, and intracavitary lesions using resectoscopes or hysteroscopy has become the mainstay of treatment, but the removal of large lesions poses a significant challenge to the surgeon. Also, the accumulation of fibroid pieces, fluid overloads, and the need for additional surgeries make these procedures more complex and tiresome. Numerous innovations in endoscopic gynaecology technology have resulted in the availability of Hysteroscopy tissue removal systems or hysteroscopy morcellators. This minimally invasive procedure has proved to be an efficient and safe alternative to conventional hysteroscopy resection. The objective of this review was to explore the clinical evidence available for the use of Hysteroscopy tissue removal systems and determine their efficacy and safety in gynaecological practice. The structure, procedural details, and characteristics of commonly used hysteroscopy tissue removal systems were thoroughly studies. Clinical performance, safety, and efficacy of these systems in comparison to other techniques were also evaluated in several uterine abnormalities. After reviewing the published literature, we concluded that the hysteroscopy tissue removal systems were more effective and safe to treat a wide range of intrauterine pathologies. The minimal fluid deficit, simultaneous cutting, and suction of tissue fragments, reduced operating time and minimum need for additional procedures with hysteroscopy tissue removal systems make it an excellent and viable option for treating a wide spectrum of uterine abnormalities in both office and operative settings.
\end{abstract}

Keywords: Intrauterine pathology; Hysteroscopic tissue removal system; Morcellator; Hysteroscopy

\section{Introduction}

Structural and functional abnormalities of the uterus rank high among several gynecological diseases. These intrauterine abnormalities can occur as intracavitary lesions, inflammatory conditions, mullerian developmental abnormalities, hyperplastic, and tumor processes such as polyps, myomas, and submucosal leiomyoma. This pathology has become the major cause of menstrual disorders such as abnormal vaginal bleeding and reproductive disorders such as repeated miscarriages and reduced fertility $[1,2]$.

Evaluation of uterine cavity and surgical resection of polyps, sub mucosal leiomyoma and other adhesions inside the uterus has become the mainstay of treatment of abnormal uterine bleeding, mullerian abnormalities, recurrent abortions, and infertility. Hysteroscopy has revolutionized gynaecological practices and it has become the major tool of choice for the evaluation and treatment of intrauterine diseases, during the last decade [3]. Traditionally operative resecoscopy or hysteroscopy was performed using monopolar or bipolar currents for resection of pathological tissue, but various risks were associated with this procedure such as fluid overload system, uterine perforation, and cervical trauma. Although these risks were directly dependent on the experience of the surgeon, the resection time and removal of tissue were related to the size of endometrial lesions and thus it becomes a complex and tedious process [4,5].

Novel methodological and technological improvements in conventional operative hysteroscopy have led to the development of Hysteroscopic Tissue Removal (HTR) systems, which has opened a new era in gynaecological practice [6]. This approach to 
tissue removal deploys a fluid management device that improves the chances to eliminate enormous amounts of tissues in an easy and faster method. It has made the resection and removal of pathological tissue more effective, useful and safe. A large number of clinical trials had suggested the clinical efficiency of HTR systems, but position of hysteroscopy and HTR systems in gynaecological practice is not clear [3,5].

In this review, we will investigate the available pieces of literature related to the utility of HTR systems among gynaecological practices while discussing the procedural details, clinical efficacy, safety, benefits, and challenges of this procedure.

\section{HTR Systems: Defining its Indications, Structural and Procedural Details}

HTR systems or hysteroscopic morcellation is a minimally invasive procedure indicated to treat a wide array of pathologies inside a women uterus such as polyps, uterine myomas, and remove placental remnants among other gynecological conditions [7].

\section{Structural details}

The HTR systems were developed to overcome the limitations of traditional hysteroscopic procedures and reduce the risk and complication associated with them. Most of HTR systems share a similar structural design, which includes a hand piece hysteroscope, cutting blades, fluid management system, power control unit, footswitch, and software. The functions of a HTR system are as explained as below:

- Power Control Unit: Inside this unit, an electric motor is placed which is activated by a foot pedal. After the start, the blade in the hysteroscope is driven by motor. The digital display of the control unit shows speed (in revolution per minute or $\mathrm{rpm}$ ), function mode (rotation/reciprocation), and surgical time, which corresponds to the working time of the blade.

- Footswitch: It consists of a foot pedal, which helps to activate/deactivate the electric motor. It also consists of a button, which also allows pre-setting the mode of function of the blade (rotation, or rotation with reciprocation) depending on the model. An additional button is also present on the foot pedal to set activate window lock before the start of the procedure.

- Hand-piece: Its major function is to drive the surgical blades and provide suction flow control. It should be always held with the dominant hand since the blade is placed in the operative channel of the dedicated hysteroscope

- Hysteroscope: It is a device that uses rod lenses or fibres for visualization of polyps and is compatible with the customdesigned or generic fluid management system. A wide range and sizes of rigid hysteroscopes are available with an offset proximal eyepiece.

- Shaver blades: Several motorized blades have been developed by different companies with a wide range of diameters and window sizes. The uterine cavity is accessible to all blades through hysteroscope working channel. Each blade consists of an inner hollow rotating/cannula and outer hollow sheath with corresponding windows for cutting and suction simultaneously. The cutting blade easily penetrates the tissue, and its speed should be adjusted so that there is enough time for tissue fragments to enter. The resected tissue aspires through a vacuum source in an outer tube through a side facing cutting window.

- Window lock: It is used to stop the blade window in its closed position, before and after its activation. It keeps the uterine cavity distended.

- Irrigation and suction system: A normal saline solution is commonly used as distension media in the HTR systems. An electronically controlled irrigation pump and suction device system are used to deliver saline to reduce the risk of fluid intravasation syndrome. Usually, an automated fluid system is employed which continuously measures the intrauterine pressure, distending media input and output, and the volume of fluid deficit. During procedure, it also helps to visualize the intrauterine cavity. Integrated vacuum suction is used to apply negative pressure through the central cylinder of the blade and brings the tissue fragments into the cutting window [6].

\section{Procedural details}

It works on the principle of suction and aspiration is generally performed under local or general anaesthesia. Following the anaesthesia, a routine diagnostic hysteroscopy is performed and distending media is introduced to confirm the presence of the polyps. The hysteroscopic morcellation or tissue removal system is passed to cut the abnormal tissue and remove the fragments using suction.

The speed of tissue removal is dependent on the contact time of the cutting window with the tissue, the consistency of tissue, and the speed of the blade at which it resects and aspirates the tissue. This procedure allows good visibility as no gas bubbles are formed throughout the procedure and instant removal of tissue. Furthermore, the simultaneous cutting and aspiration of tissue optimizes removal of specimen removal and also reduces the need for additional instruments and multiple insertions of the device in the uterine cavity $[6,8]$.

\section{Commonly Used HTR Systems}

The most commonly available and widely used HTR systems are TruClear, MyoSure LITE and Omni Hysteroscope, Integrated 
Citation: Gururaj R (2021) A Review on the Use of Hysteroscopy Tissue Removal System in Gynaecology. Gynecol Obstet Open Acc 5: 142. DOI: 10.29011/25772236.100142

Bigatti Shaver, and Symphion system. These systems have received approval from US Food and Drug Administration (FDA). The structural components of these surgical models are similar but there exists some differences in the characteristics of hysteroscope and cutting device (Table 1).

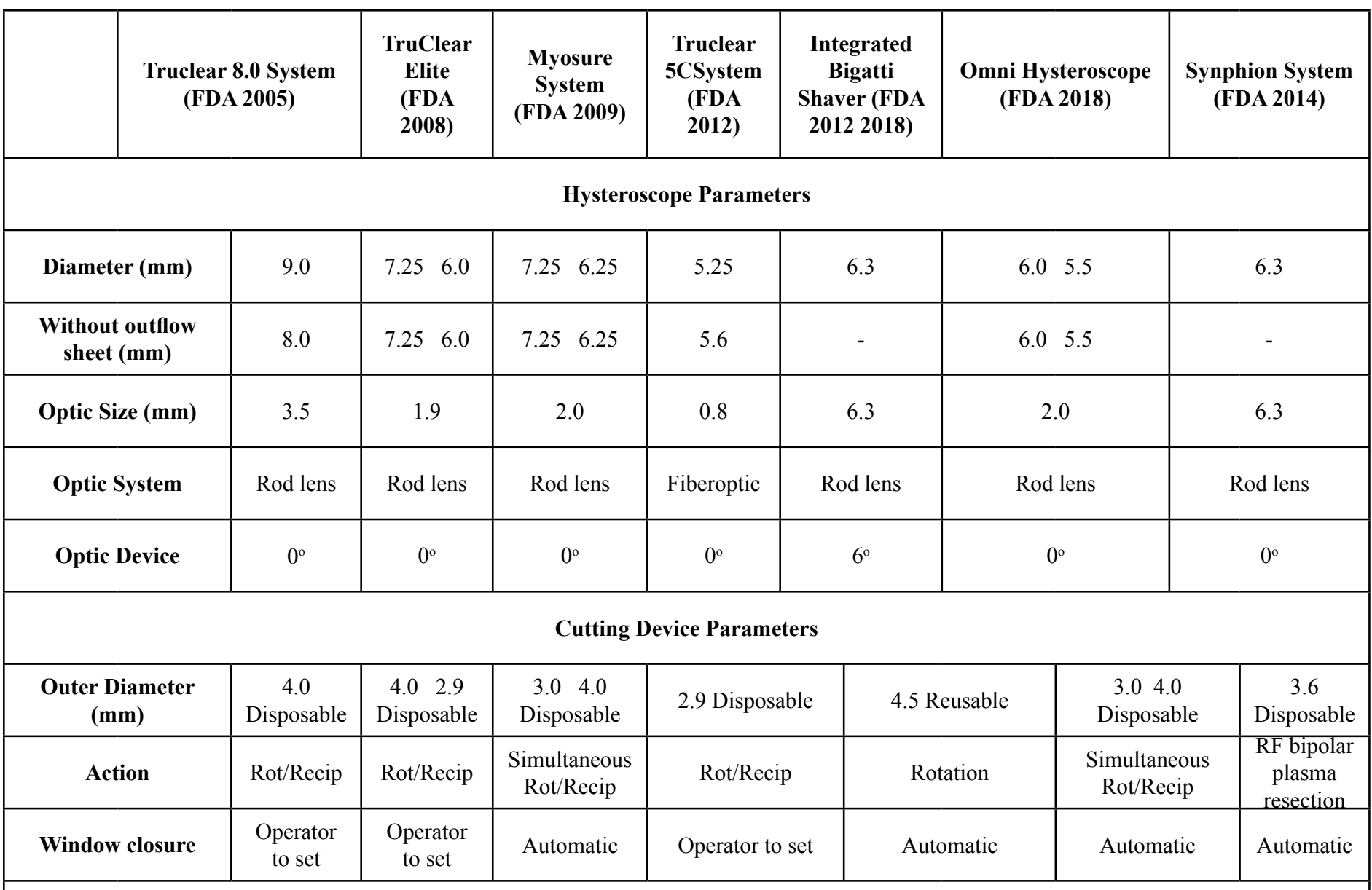

Abbreviations used: Millimetre: mm; Rotation: Rot; Reciprocation: Recip; Radiofrequency: RF

Table 1: Characteristics of widely used HTR systems.

These HTR systems are associated with clinical benefits such as reduced operational time, higher rates of resection, and more importantly higher acceptability in patients [6-9].

\section{Efficacy and Safety of HTR Systems Compared to Conventional Operative Procedures}

Clinical evidence so far has suggested that HTR systems are an effective and clinically safe alternative to conventional hysteroscopy procedures to treat structural abnormalities inside uterus [5]. A consensus statement from the American College of Gynecology (ACOG) American Association of Gynecologic Laparoscopists (AAGL) also reported the conservative management may be accurate but HTR can be useful for removal of uterine fibroids and polyps [9].

\section{HTR Systems for Resection of Endometrial Polyps}

Several randomized trials have shown the feasibility of the HTR system for resection of endometrial polyps compared to conventional systems. Emanuel and Wamsteker in 2005 and van Dongen, et al. in 2008 reported that the manual HTR system is faster than the conventional loop resectoscopy with equal removal of polyps in operation settings [10,11]. In 2011, the findings of a retrospective trial reported that the success of HTR in removing around 278 polyps without causing any complications [12]. Another two studies done in 2014 and 2015 by Smith PP and Pampalona, et al. respectively, demonstrated a higher and complete removal of polyps in a short procedure time with manual HTR systems in comparison to the bipolar electrode $[13,14]$. In 
2019, Ceci, et al. also determined that the manual HTR system was effective and feasible for removing large-sized endometrial polyps in office settings [15].

In 2013, AlHilli, et al. assessed the polyp recurrence following conventional resectoscopy and manual HTR systems and determined that the recurrence rates of the polyp were significantly low with manual HTR systems compared to resectoscopy [16]. In another study by Ceci, et al. in 2020, it was estimated that the oneyear polyp recurrence rates were reduced in small-sized manual HTR systems compared to the bipolar electrode when used in office settings. However, the difference in polyp recurrence rates was not statistically significant [17].

\section{HTR Systems for Resection of Myoma}

Complete resection and removal of myoma using a manual HTR system are significantly dependent on the size and type of myoma. Keeping these criteria in mind, various clinical studies have assessed the cut-off values for diameter and volume of myoma to obtain the best results with a low risk of complication using HTR [18]. Bigatti, et al. conducted a clinical study in 2014 to determine the advantages as well outcomes of shaver techniques suggesting treatment of $93.5 \%$ of type 0 or 1 myoma less than 3 $\mathrm{cm}$ and $62.5 \%$ of type 2 myomas in a single step procedure [19]. A study published in 2015 showed no significant differences in complete removal rates of types 0,1 , or 2 submucous myomas between manual HTR system and bipolar resectoscope [20].

Arnold $\mathrm{A}$ and his colleagues reported $66 \%$ removal of entire pathology for leiomyomas [21]. A study published in 2016 reported less fluid deficit among women who were treated with myomectomy with morcellation compared to those treated with resectoscopy [22]. The findings of a systematic review (2017), reported the higher efficacy of manual HTR systems for excision of submucous type 0-1 myoma but lower efficacy in type 2 submucous fibroids. Also, it was demonstrated that Myosure and Truclear tissue removal systems have similar rates of resection [23].

Liang, et al. showed the feasibility of manual HTR systems for removing type 2 myomas combining manual HTR morcellation with cold scissors and grasping forceps in an operating room in his observational study [24]. A study by Rubino, et al. reported significant improvements in clinical symptoms and patient quality of life at 12 months when myomectomy was performed using HTR systems [25].

\section{HTR Systems for Endometrial Sampling}

The utility of manual HTR systems has also been proposed for the removal of target endometrial tissue without causing any damage to surrounding healthy endometrium. It involves performing manual HTR systems with a 'curettage' under direct visualization of the uterine cavity (visual D\&C) thus providing an alternative to the classic blind D\&C [6]. In 2015, Franchini, et al. determined that adequate tissue for histological diagnosis can be obtained while removing endometrial polyps using manual HTR systems. Also, the tissue samples obtained and submitted for histological diagnosis were without any thermal artifacts [26].

Rosenblatt, et al. in 2017 demonstrated the superiority of manual HTR systems over dilation and curettage procedure for the collection of targeted large quantities of tissues suitable for precise and explicit histological analysis among postmenopausal bleeding patients [27]. However, Lindheim, et al. study findings were not in line with previous studies and it questioned the pathologist ${ }^{\star} \mathrm{s}$ ability of manual HTR systems to accurately perform histological reads as up to $20 \%$ of the malignant specimens were under-diagnosed and $30 \%$ were over diagnosed [28].

\section{HTR Systems for Resection of Endometrial Adhesions/Septum and Infertility Treatment}

The presence of structural abnormalities in the uterus such as polyps, fibroids, endometrial septum's, and intrauterine adhesions may prevent implantation and thus leads to fertility problems. Removal of these pathological lesions before intrauterine insemination can significantly improve the chances of fertility. HTR systems have been effective for the removal of fibroids and polyps but there is insufficient evidence regarding the efficacy of HTR for resection of endometrial adhesions/septum [29].

Simons, et al. in 2011 have proposed that the use of manual HTR systems may be effective and safe for removal of avascular uterine septum effective with a few complications compared to resectoscopy. It also reduced operating time and complete removal instead of the transaction can cause less intrauterine adhesion formation [30]. Another study has also reported that dissection of endometrial septum hysteroscopically might improve the pregnancy rates [31].

\section{HTR Systems for Resection of Retained Products of Conception (RPOC)}

The number and frequency of patients with RPOC have been increasing after any form of pregnancy termination or contraception. These RPOCs were treated with blind dilation and curettage $(\mathrm{D} \& \mathrm{C})$ traditionally, which had increased chances of developing complications such as uterine perforation, infections, and formation of intrauterine adhesions [6]. Manual HTR systems can be a viable option for the removal of RPOC as it allows easy removal of contraception products without causing any damage to the endometrium and also reduces the risk of developing postoperative adhesions [32].

Hamerlynck, et al. first confirmed the use of manual HTR systems for the removal of RPOC [33]. Rein, et al in 2011 and 


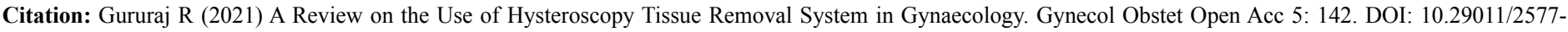
2236.100142

Ikhena, et al in 2016 evaluated the efficacy of manual HTR systems and their findings reported that manual HTR systems can be an effective alternative to conventional blind sharp or suction curettage for treating RPOC $[34,35]$. Van Wessel, et al. recently published clinical data on reproductive outcomes following HTR and reported that live birth rate was higher in patients with HTR compared to those treated with loop resection techniques [36].

\section{Benefits and Limitations of HTR Systems}

Gynaecologists have reported significant benefits of HTR such as shorter operation time, higher patient acceptability, and high resection rates. HTR is more successful for complete removal of endometrial lesions compared to conventional resectoscopy. These higher success rates of complete removal of pathology can be related to reduced operation time and fluid deficit. Furthermore, the complications associated with conventional systems and requirement of additional treatments has also decreased with HTR systems [5]. According to MAUDE (Manufacture and User Facility Device Experience) database, the complications associated with hysteroscopic morcellation is less than $0.1 \%$, which is less than conventional hysteroscopic surgery [6].

Despite these benefits, some life-threatening complications such as fluid overload, uterine perforation, intubation, risk of cancer and admission to intensive care units have been reported with HTR, but the prevalence of these complications is extremely low $[6,37]$. Other potential limitations with these systems includes higher cost, restricted sterilization of bleeding vessels and scarcity of data on its efficacy for type II leiomyomas resection [9]. There is a need to investigate the limitations of HTR further.

\section{Conclusion and Future Directions}

To the best of our knowledge, HTR is a great and highly feasible choice for the complete removal of intrauterine abnormalities and lesions among patients requiring surgical treatment. It is also a viable option for obtaining adequate quality tissue for histological analysis without causing any significant damage to the surrounding healthy endometrium. Using HTR can also improve the operating time and visual identification while avoiding the need for multiple insertions into the uterine cavity compared to the conventional hysteroscope/resectoscope. However, there is a need to conduct additional trials for investigating the utility of HTR in other gynaecological pathologies such as large sub mucosal myomas, placental remnants, uterine septum, adhesions in endometrium and impotency. Other aspects such learning curve and cost-effectiveness also needs to be evaluated and addressed in future studies. Based on the current data, gynaecologists can avoid performing intrauterine blind procedures and choose manual HTR systems, if available.

\section{References}

1. Zafarani F, Ahmadi F (2013) Evaluation of intrauterine structural pathology by three-dimensional sonohysterography using an extended imaging method. Int J Fertil Steril 7: 1-6.

2. Sulima AN, Kolesnikova IO, Davydova AA, Kriventsov MA (2020) Hysteroscopic and morphological assessment of intrauterine pathology in different age periods. J Obst Women Dis 69: 51-58.

3. Carneiro MM (2018) What is the role of hysteroscopic surgery in the management of female infertility? A review of the literature. Surg Res Pract 2014: 105412.

4. Mahmud A, Smith P, Clark J (2015) Role of hysteroscopy in the diagnosis of menstrual disorder. Best Pract Res Clin Obstet Gynaecol 29: 898-907.

5. Yin X, Cheng J, Ansari SH, Campo R, Di W, et al. (2018) Hysteroscopic tissue removal systems for the treatment of intrauterine pathology: a systematic review and meta-analysis. Facts Views Vis Obgyn 10: 207213.

6. Franchini M, Ceci O, Casadio P, Carugno J, Giarre G, et al. (2021) Mechanical hysteroscopic tissue removal or hysteroscopic morcellator: understanding the past to predict the future. A narrative review. Facts Views Vis Obgyn 13: 193-201.

7. Haimovich S, Tanvir T (2021) A Mini-Review of Office Hysteroscopic Techniques for Endometrial Tissue Sampling in Postmenopausal Bleeding. J Midlife Health 12: 21-29.

8. Vitale SG, Sapia F, Rapisarda A, Valenti G, Santangelo F, et al. (2017) Hysteroscopic Morcellation of Submucous Myomas: A Systematic Review. BioMed Res Int 2017: 6848250.

9. Yang L, Chaudhari A, AAGL, ACOG Committee (2018) The Use of Hysteroscopy for the Diagnosis and Treatment of Intrauterine Pathology. Committee on Gynecologic Practice 135: e138-e143.

10. Emanuel MH, Wamsteker K (2005) The Intra-Uterine Morcellator: a new hysteroscopic operating technique to remove intrauterine polyps and myomas. J Minim Invasive Gynecol 12: 62-66.

11. van Dongen $\mathrm{H}$, Emanuel $\mathrm{MH}$, Wolterbeek $\mathrm{R}$, Trimboss JB, Jansen $\mathrm{FW}$ (2008) Hysteroscopic morcellator for removal of intrauterine polyps and myomas: a randomized controlled pilot study among residents in training. J Minim Invasive Gynecol 15: 466-471.

12. Hamerlynck TW, Dietz V, Schoot BC (2011) Clinical implementation of the hysteroscopic morcellator for removal of intrauterine myomas and polyps. A retrospective descriptive study. Gynecol Surg 8: 193-196.

13. Smith PP, Middleton LJ, Connor M, Clark TJ (2014) Hysteroscopic morcellation compared with electrical resection of endometrial polyps: A randomized controlled trial. Obstet Gynecol 123: 745-751.

14. Pampalona JR, Bastos MD, Moreno GM, Pust AB, Montesdeoca GE, et al. (2015) A comparison of hysteroscopic mechanical tissue removal with bipolar electrical resection for the management of endometrial polyps in an ambulatory care setting: Preliminary results. J Minim Invasive Gynecol 22: 439-445.

15. Ceci O, Franchini M, Cannone R, Giarrè G, Bettocchi S, et al. (2019) Office treatment of large endometrial polyps using TruClear5C: Feasibility and acceptability. J Obstet Gynaecol Res 45: 626-633. 
Citation: Gururaj R (2021) A Review on the Use of Hysteroscopy Tissue Removal System in Gynaecology. Gynecol Obstet Open Acc 5: 142. DOI: 10.29011/25772236.100142

16. AlHilli MM, Nixon KE, Hopkins MR, Weaver AL, Laughlin-Tommaso SK, et al. (2013) Long-term outcomes after intrauterine morcellation vs hysteroscopic resection of endometrial polyps. J Minim Invasive Gynecol 20: 215-221.

17. Ceci O, Franchini M, Cardinale S, Cannone R, Giarrè G, et al. (2020) Comparison of endometrial polyp recurrence infertile women after office hysteroscopic endometrial polypectomy using two widely spread techniques. J Obstet Gynaecol Res 46: 2084-2091.

18. Friedman JA, Wong JMK, Chaudhari A, Tsai S, Milad MP. (2018) Hysteroscopic myomectomy: a comparison of techniques and review of current evidence in the management of abnormal uterine bleeding. Curr Opin Obstet Gynecol 30: 243-251.

19. Bigatti G, Franchetti S, Rosales M, Baglioni A, Bianchi S. (2014) Hysteroscopic myomectomy with the IBS $®$ Integrated Bigatti Shaver versus conventional bipolar resectoscope: a retrospective comparative study. Gynecol Surg 11: 9-18.

20. Hamidouche A, Vincienne M, Thubert T, Trichot C, Demoulin G, et al. (2015) Operative hysteroscopy for myoma removal: morcellation versus bipolar loop resection. J Gynecol Obstet Biol Reprod (Paris) 44: 658-664.

21. Arnold A, Ketheeswaran A, Bhatti M, Nesbitt-Hawes E, Abbott J (2016) A prospective analysis of hysteroscopic morcellation in the management of intrauterine pathologies. J Minim Invasive Gynecol 23: $435-441$

22. Shazly SAM, Laughlin-Tommaso SK, Breitkopf DM, Hopkins MR, Burnett TL, et al. (2016) Hysteroscopic morcellation versus resection for the treatment of uterine cavitary lesions: a systematic review and meta-analysis. J Minim Invasive Gynecol 23: 867-877.

23. Vitale SG, Sapia F, Rapisarda AMC, Valenti G, Santangelo F, et al. (2017) Hysteroscopic morcellation of submucous myomas: a systematic review. Biomed Res Int 2017: 6848250.

24. Liang Y, Ren Y, Wan Z, Guo L, Dong J, et al. (2017) Clinical evaluation of improved MyoSure hysteroscopic tissue removal system for the resection of type II submucosal myomas. Medicine (Baltimore) 96: e9363.

25. Rubino RJ, Lukes JS (2015) Twelve-month outcomes for patients undergoing hysteroscopic morcellation of uterine polyps and myomas in an office or ambulatory surgical center. J Minim Invasive Gynecol 22: $285-290$.

26. Franchini M, Zolfanelli F, Gallorini M, Giarre G, Fimiani R, et al. (2015) Hysteroscopic polypectomy in an office setting: specimen's quality assessment for histopathological evaluation. Eur J Obstet Gynecol Reprod Biol 189: 64-67.
27. Rosenblatt P, Barcia S, Di Sciullo A, Warda H (2017) Improved adequacy of endometrial tissue sampled from postmenopausal women using the MyoSure Lite hysteroscopic tissue removal system versus conventional curettage. Int J Womens Health 27: 789-794.

28. Lindheim SR, Lincenberg K, Wood MA, Kemner E, Burns MK, et al. (2019) The impact of hysteroscopic tissue removal systems on histopathologic analysis for benign and cancerous endometrial pathology: an ex vivo study. J Obstet Gynaecol India 69: 182-187.

29. Bosteels J, Kasius J, Weyers S, Broekmans FJ, D'Hooghe TM, et al. (2015) Hysteroscopy for treating subfertility associated with suspected major uterine cavity abnormalities. Cochrane Database Syst Rev 12: CD009461.

30. Simons M, Hamerlynck TW, Abdulkadir L, Schoot BC (2011) Hysteroscopic morcellator system can be used for removal of a uterine septum. Fertil Steril 96: 118-121.

31. Practice Committee of the American Society for Reproductive Medicine (2016) Uterine septum: a guideline. Fertil Steril 106: 530-540.

32. Ansari SH, Bigatti G, Aghssa MM (2018) Operative hysteroscopy with the Bigatti shaver $\left(\mathrm{IBS}^{\circledR}\right)$ for the removal of placental remnants. Facts Views Vis Obgyn 10: 153-159.

33. Hamerlynck TW, Blikkendaal MD, Schoot BC, Hanstede MMF, Jansen FW (2013) An alternative approach for removal of placental remnants: Hysteroscopic morcellation. J Minim Invasive Gynecol 20: 796-802.

34. Rein DT, Schmidt T, Hess AP, Volkmer A, Schondorf T, et al. (2011) Hysteroscopic management of residual trophoblastic tissue is superior to ultrasound-guided curettage. J Minim Invasive Gynecol 18: $774-$ 778.

35. Ikhena DE, Bortoletto $P$, Lawson AK, Confino R, Marsh EE, et al. Reproductive outcomes after hysteroscopic resection of retained products of conception. J Minim Invasive Gynecol 23: 1070-1074.

36. van Wessel S, Coryn N, van Vliet H, Schoot B, Weyers S, et al. (2020) Reproductive and obstetric outcomes after hysteroscopic removal of retained products of conception. J Minim Invasive Gynecol 27: 840846.

37. US Food and Drug Administration (2014) Laparoscopic Uterine Power Morcellation in Hysterectomy and Myomectomy: FDA Safety Communication. 